\title{
Safety assessment of Spirulina platensis through sprague dawley rats modeling
}

\author{
Shahid BASHIR ${ }^{1}$, Mian Kamran SHARIF², Muhammad Sameem JAVED ${ }^{3 *}$ (D), Adnan AMJAD ${ }^{3}$, \\ Ammar Ahmad KHAN ${ }^{1}$, Faiz-ul-Hassan SHAH $^{1}$, Anees Ahmad KHALIL ${ }^{1}$
}

\begin{abstract}
Health safety of spirulina (Spirulina platensis) for food application was evaluated through hematology and histopathology of liver, spleen and kidney in Sprague Dawley rats fed on three isoproteic diets maintained to $10 \%$ protein for forty five days. Three groups of rats were maintained as control diet casein (R-C); diet containing crude spirulina (R-S) and diet containing purified spirulina protein (R-SPI). Hematological profile of the rats group fed on spirulina diets showed no significant increase in white blood cells (WBCs), while there was decreasing trend in the levels of neutrophils $(60.46 \pm 2.60 \%)$ and lymphocytes $(33.53 \pm 1.06 \%)$ in rats that were fed on spirulina diet (R-S) than the other tested experimental diet group. Histopathological examination revealed normal architecture of the liver with no abnormality in kidneys and spleen exhibiting safety of spirulina in both forms to mitigate protein energy malnutrition widely prevalent in developing countries.
\end{abstract}

Keywords: spirulina; spirulina protein isolates; hematology; histopathology; algal toxicology.

Practical Application: In the current study safety evaluation of spirulina for food applications was made. Spirulina can be used in confectionary and snack industry to prepare candies, bars and different bakery items that will not only create variety in the market but also provide highly nutritious food that will help to nourish and combat with malnutrition in children.

\section{Introduction}

Consumer demands and interest regarding use of "natural green" additives in different food products is greater than ever mainly due to food safety related issues. Spirulina consumption $(10-40 \mathrm{~g})$ has no any adverse effect on kidney, liver, reproductive and physiological functioning (Hutadilok-Towatana et al., 2010). The panel of Dietary Supplements Information Expert Committee (DSI-EC) of the United States Pharmacopeial Convention has assigned "grade A" for spirulina regarding safe for human consumption (Ku et al., 2013). In a human study, the ingestion of spirulina ( $10 \mathrm{~g} /$ day for 6 months) was found to impart no harmful health effects (Yamani et al., 2009). The Food and Drug Administration (FDA) has included spirulina in the GRAS (Generally Recognized as Safe) list and has also suggested its consumption (0.1-6g/day) on daily basis through various food products (Food and Drug Administration, 2003). Spirulina is a food complement, which can be added in regular meals in amounts varying from 1-5g (Simpore et al., 2011).

Spirulina has attained the status of "super food" due to its chlorophyll, $\beta$-carotene, phycocyanin, and mineral contents (Sullivan et al., 2011). The health benefits of spirulina are mainly due to its phytonutrients (Li et al., 2006; Kaur et al., 2009) which strengthens the immune system (Banji et al., 2013). Spirulina is good source of protein, vitamin A, D, E and B group; whereas among the minerals calcium, iron, magnesium, zinc, manganese, copper and selenium helps in improving general health and vigour (Jiwan et al., 2010; Ravi et al., 2010). The amount of iron in dry spirulina is higher than cereals which play an active role in energy utilization in the respiratory chain of mitochondria and ultimately enhanced the protein digestion and assimilation (Beard, 2001).

The major bioactive components of spirulina are phycocyanin, $\gamma$-linolenic acid, sulfated polysaccharides, mixed carotenoids, phytonutrients, and essential amino acids which are believed to play important role in improving human body defense system (Simpore et al., 2006). Among the fatty acids, palmitic, $\gamma$-linolenic and linoleic acids are the dominating fatty acids which exhibit strong free radical scavenging activity (Ambrozova et al., 2014). Spirulina also contains eicosapentaenoic acid, docosahexaenoic acid and arachidonic acid that are easily absorbed by human cells (Simpore et al., 2006).

The role of spirulina as an antiviral, antitumor, antibacterial, anti inflammatory, anticancer, anti-HIV agent and as a food additive has been well established. The phycocyanin and $\gamma$-linolenic acid stimulates the immunological system and prostaglandin synthesis that have positive impact on blood pressure regulation (Francavilla et al., 2010; Ibañez \& Cifuentes, 2013). Spirulina produces immune stimulating effect by enhancing the resistance against infections and stimulating the production of antibodies and cytokines, sulfolipids that proved to be effective against HIV and carcinogenesis.

Hematological profile was improved after consumption of spirulina that contained highly available form of iron, calcium, magnesium, copper, vitamin $\mathrm{B}_{6} \& \mathrm{~B}_{12}$, and folic acid which are essential for haemopoiesis (Kaur et al., 2009). The regular consumption (1-8 g/day) of spirulina significantly alleviates 
malnutrition related abnormalities in human subjects during 24 weeks intervention (Marles et al., 2011). So, that the current study is designed to establish the safety evaluation of Spirulina platensis by preparation of spirulina food bars from protein isolates and spirulina. The prepared bars were fed to rats and histopathological and hematological examination of rats were carried out assess the safety level of spirulina.

\section{Materials and methods}

Raw materials: Spray-dried spirulina (Spirulina platensis) strain Pacifica was purchased from Cyanotech Corporation, Hawaii, USA. Spirulina protein isolates were prepared at lab following the method of Gerde et al. (2013).

Animals: Ninety healthy adult male Sprague Dawley rats were obtained from the National Institute of Health (NIH) Islamabad, Pakistan. The animals were kept under the similar management conditions in animal room of National Institute of Food Science and Technology, University of Agriculture, Faisalabad, Pakistan. The rats were kept in clean iron cages at ambient temperature $\left(27-29^{\circ} \mathrm{C}\right)$ with a $12 / 12$ hour period of light/dark.

Experimental design: After seven days of acclimatization, rats were randomly divided into three equal groups and fed on control diet (R-C), diet containing spirulina (R-S) and spirulina

Table 1. Formulation for experimental diet containing protein and vitamin balanced components.

\begin{tabular}{lccc}
\hline \multicolumn{1}{c}{ Diet Constituents } & S diet & SPI diet & Casein diet \\
\hline Spirulina (S) & 15.89 & 0.0 & 0.0 \\
Spirulina protein isolate (SPI) & 0.0 & 13.51 & 0.0 \\
Casein & 0.0 & 0.0 & 10.37 \\
Corn oil & 5.0 & 5.0 & 5.0 \\
Mineral mixture & 5.0 & 5.0 & 5.0 \\
Vitamin mixture & 1.0 & 1.0 & 1.0 \\
N-free mixture & 73.11 & 75.49 & 78.63 \\
Total diet weight & 100 & 100 & 100 \\
\hline
\end{tabular}

Values are shown as gram; all the diets contain $10 \%$ protein (spirulina $62.93 \%$ and SPI $74 \%$ protein) protein isolates diet (R-SPI) for 45 days. Experimental diets (Table 1) were provided twice a day usually in the morning and evening. However, drinking water was available throughout 24 hours. At the end of each study interval the rats were sacrificed according to the rules laid down by the Society of Ethics of Animals, University of Agriculture Faisalabad, Pakistan.

Sample collection and analysis: Blood samples were collected on $0,15,30$ and 45 days. For the collection of blood samples five rats from each group were sacrificed at each sampling time and the blood of rats was collected individually.

Hematological parameters: Blood samples used for hematological analysis were collected into EDTA-containing tubes. Hematological analyses for red and white blood cells indices were carried out using the hematological analyzer (Medonic M, Boule Medical Stockholm, Sweden) at each study intervals following the procedure described by Elmalawany et al. (2014).

Histopathology: Rats were sacrificed immediately after each study interval to collect body organs including liver, kidney and spleen of each group. The organs were excised, washed and preserved in $10 \%$ neutral formalin solution followed by dehydration of 5-6 $\mu \mathrm{m}$ thick sections in alcohol, embedded in paraffin stained with haematoxylin and eosin (H\&E) and observed under light microscope (Labomed Lx4, Labo America Inc., CA, USA.) for histopathological changes (Banji et al., 2013; Sarumathi et al., 2014).

Statistical analysis: The collected data was statistically analyzed using the method described by Steel et al. (1997).

\section{Results and discussion}

\subsection{Hematological aspects}

In current investigation, the effect of spirulina based diets on blood indices like red blood cells and white blood cells were examined.

Means for effect of spirulina and SPI supplemented diets on red blood cells (RBC) in rats (Table 2) showed slightly high value $(8.72 \pm 1.02$ cells $/ \mathrm{pL})$ in rats fed on diet containing spirulina

Table 2. Means \pm SD of blood parameters in rats fed with crude spirulina and purified protein of spirulina supplemented diets during 45 days of experimental trials.

\begin{tabular}{|c|c|c|c|c|c|c|c|c|c|c|c|c|}
\hline \multirow{2}{*}{$\begin{array}{c}\text { Blood } \\
\text { Parameters }\end{array}$} & \multicolumn{3}{|c|}{0} & \multicolumn{3}{|c|}{15} & \multicolumn{3}{|c|}{30} & \multicolumn{3}{|c|}{45} \\
\hline & $\mathrm{R}-\mathrm{C}$ & R-S & R-SPI & $\mathrm{R}-\mathrm{C}$ & R-S & R-SPI & $\mathrm{R}-\mathrm{C}$ & R-S & R-SPI & R-C & R-S & R-SPI \\
\hline $\begin{array}{l}\text { RBC } \\
\text { (cells/pL) }\end{array}$ & $8.54 \pm 0.71$ & $8.65 \pm 0.21$ & $8.71 \pm 0.89$ & $8.74 \pm 0.94$ & $8.77 \pm 0.62$ & $8.63 \pm 0.66$ & $12.90 \pm 0.52$ & $13.00 \pm 0.76$ & $13.33 \pm 0.59$ & $8.77 \pm 0.53$ & $8.76 \pm 1.31$ & $8.77 \pm 0.41$ \\
\hline $\begin{array}{l}\text { Hemoglobin } \\
(\mathrm{g} / \mathrm{L})\end{array}$ & $12.31 \pm 0.09$ & $12.51 \pm 0.74$ & $12.48 \pm 0.31$ & $12.58 \pm 0.84$ & $12.66 \pm 0.92$ & $12.68 \pm 0.18$ & $12.90 \pm 0.52$ & $13.00 \pm 0.76$ & $13.33 \pm 0.59$ & $13.38 \pm 1.11$ & $13.40 \pm 1.12$ & $13.31 \pm 1.16$ \\
\hline $\begin{array}{l}\text { Hematocrit } \\
(\%)\end{array}$ & $33.62 \pm 1.52$ & $34.15 \pm 1.61$ & $34.16 \pm 1.85$ & $34.25 \pm 1.90$ & $33.80 \pm 1.92$ & $34.30 \pm 1.63$ & $34.66 \pm 1.62$ & $34.61 \pm 1.68$ & $34.11 \pm 1.35$ & $35.14 \pm 2.12$ & $34.13 \pm 1.57$ & $34.20 \pm 1.71$ \\
\hline $\operatorname{MCV}(\mathrm{f} / \mathrm{L})$ & $56.70 \pm 2.20$ & $57.50 \pm 2.21$ & $57.52 \pm 2.32$ & $56.61 \pm 3.20$ & $56.67 \pm 3.15$ & $57.60 \pm 3.22$ & $57.45 \pm 2.36$ & $57.40 \pm 2.32$ & $56.53 \pm 2.21$ & $57.68 \pm 2.23$ & $57.53 \pm 2.29$ & $57.48 \pm 3.21$ \\
\hline $\begin{array}{l}\text { WBC } \\
\text { (cells/nL) }\end{array}$ & $14.44 \pm 0.83$ & $14.68 \pm 0.76$ & $14.74 \pm 0.62$ & $15.46 \pm 0.81$ & $15.52 \pm 0.86$ & $15.84 \pm 0.91$ & $15.78 \pm 0.66$ & $15.59 \pm 0.73$ & $15.85 \pm 0.65$ & $16.49 \pm 0.77$ & $16.70 \pm 0.65$ & $16.80 \pm 0.47$ \\
\hline $\begin{array}{l}\text { Neutrophils } \\
(\%)\end{array}$ & $65.13 \pm 2.80$ & $64.27 \pm 2.88$ & $65.22 \pm 2.89$ & $61.02 \pm 2.64$ & $62.69 \pm 2.69$ & $64.23 \pm 2.74$ & $62.42 \pm 2.70$ & $62.45 \pm 2.74$ & $62.87 \pm 2.43$ & $60.42 \pm 2.51$ & $60.46 \pm 2.60$ & $59.72 \pm 2.40$ \\
\hline $\begin{array}{l}\text { Monocytes } \\
(\%)\end{array}$ & $5.22 \pm 0.31$ & $5.37 \pm 0.27$ & $5.44 \pm 0.22$ & $5.78 \pm 0.25$ & $5.75 \pm 0.21$ & $5.64 \pm 0.29$ & $6.30 \pm 0.22$ & $6.28 \pm 0.23$ & $6.34 \pm 0.20$ & $6.31 \pm 0.20$ & $6.40 \pm 0.35$ & $6.36 \pm 0.31$ \\
\hline $\begin{array}{l}\text { Lymphocytes } \\
(\%)\end{array}$ & $35.94 \pm 1.64$ & $36.54 \pm 1.52$ & $36.49 \pm 1.39$ & $34.13 \pm 1.41$ & $34.17 \pm 1.49$ & $34.23 \pm 1.64$ & $33.55 \pm 1.57$ & $33.08 \pm 1.61$ & $33.59 \pm 1.58$ & $33.49 \pm 2.01$ & $33.53 \pm 1.06$ & $33.10 \pm 1.42$ \\
\hline $\begin{array}{l}\text { Eosinophils } \\
(\%)\end{array}$ & $1.16 \pm 0.22$ & $1.15 \pm 0.27$ & $1.18 \pm 0.31$ & $1.31 \pm 0.20$ & $1.32 \pm 0.25$ & $1.30 \pm 0.29$ & $1.39 \pm 0.31$ & $1.40 \pm 0.29$ & $1.41 \pm 0.24$ & $1.50 \pm 0.35$ & $1.52 \pm 0.33$ & $1.53 \pm 0.26$ \\
\hline
\end{tabular}


protein isolates (R-SPI) with non-significantly differences in rat group fed on spirulina diet $(8.71 \pm 1.11$ cells $/ \mathrm{pL})$ and diet without spirulina $(8.70 \pm 2.96$ cells $/ \mathrm{pL})$. There was increase in RBC (1.27\%) this was due to gain in body size and weight (Figure 1). Overall, there was nonsignificant rise in RBC of experimental rats after provision of therapeutic diets. Means for hemoglobin $(\mathrm{Hb})$ levels in rats (Table 2) exposed slightly elevated value $(12.95 \pm 0.89 \mathrm{~g} / \mathrm{L})$ in rats fed on spirulina protein isolates diet (R-SPI) whereas lower value $(12.89 \pm 0.91 \mathrm{~g} / \mathrm{L})$ were noticed in rats fed on spirulina diet followed by $12.79 \pm 1.12 \mathrm{~g} / \mathrm{L}$ in rats fed on control diet (R-C). During the study intervals, the highest hemoglobin value $(13.36 \pm 1.14 \mathrm{~g} / \mathrm{L})$ was observed at end of study. Overall, there was significant rise (7.11\%) in R-S group at end of the study (Figure 1).

Hematocrit (HCT) value revealed the total mass of the cells in unit of blood volume. It is deduced from the means for effect of different diets and study intervals on hematocrit levels in rats (Table 2) that treatment did not impart variation in the rat groups, however the highest hematocrit $(34.42 \pm 1.41 \%)$ was noticed in rats fed on control diet (R-C) whereas slightly lower value $(34.19 \pm 2.34 \%)$ was shown in R-SPI and R-S rats group $(34.17 \pm 1.22 \%)$. Overall, there was non-significant rise in hematocrit and values were ranged from $33.62 \pm 1.52$ to $35.14 \pm 2.12 \%$ in all experimental groups after the provision of diets for 45 days. The mean corpuscular volume (MCV) indicates the size of red blood cells. Means for mean corpuscular volume in rat groups (Table 2) exhibited $57.28 \pm 2.14 \mathrm{f} / \mathrm{L}, 57.27 \pm 2.61 \mathrm{f} / \mathrm{L}$ and $57.11 \pm 2.53 \mathrm{f} / \mathrm{L} \mathrm{MCV}$ in rats fed on diets containing SPI, spirulina and casein, respectively. During the study intervals, the highest MCV $(57.56 \pm 2.61 \mathrm{f} / \mathrm{L})$ was observed at end of study. As a whole, there was non-significant rise in MCV of experimental rats during the study period and values varied from $56.53 \pm 2.21$ to $57.68 \pm 2.23 \mathrm{f} / \mathrm{L}$ in all experimental groups.

The colorless elements of the blood of the mammals, leukocytes play a vital role in the defense against infectious actions. Means for effect of spirulina containing diets on white blood cells count (WBC) in rat groups (Table 2) showed the highest WBC
$(15.81 \pm 0.78$ cells $/ \mathrm{nL})$ in rats fed on spirulina protein isolates diet (R-SPI) whereas considerably lower WBC were present in rats group fed on spirulina diet $(15.62 \pm 0.82$ cells $/ \mathrm{nL})$ and control diet group $(15.54 \pm 0.94$ cells $/ \mathrm{nL})$, respectively. Mean value of white blood cells count was increased significantly $(13.97 \%)$ at 45 days of the study in R-SPI group. Overall, WBC was ranged from $14.44 \pm 0.83$ to $16.80 \pm 0.47$ cells $/ \mathrm{nL}$ in all experimental groups. Neutrophils have a vital role in the pathogenesis of a broad range of diseases, including infections, autoimmunity, chronic inflammation and cancer. It is evident from the means for neutrophils (Table 2) that neutrophils were $63.01 \pm 2.60$, $62.47 \pm 2.52$ and $62.25 \pm 2.45 \%$, respectively in rats fed on spirulina protein isolates diet (R-SPI), spirulina diet (R-S) and control diet, respectively. During 45 day study, the neutrophils were observed decreasing trend $(-8.43 \%)$ at the end of study in R-SPI diet group (Figure 1). Means for effect of different diets and study intervals on monocytes in rats (Table 2) showed $5.95 \pm 0.36 \%$ monocytes in rats fed on diet containing spirulina, $5.94 \pm 0.34 \%$ in rat group fed on spirulina protein isolates and $5.90 \pm 0.26 \%$ control diet. Monocytes revealed increasing trend maximum value (19.18\%) shown by R-SPI group at the end of 45 day study (Figure 1).

Means for lymphocytes in various rats groups (Table 2) revealed $34.35 \pm 1.53$ to $34.33 \pm 1.40$ and $34.28 \pm 1.48 \%$ lymphocytes in rats fed on R-SPI, R-S and control diet, respectively. Overall, lymphocytes varied from $33.08 \pm 1.61$ to $36.54 \pm 1.52 \%$ in all experimental rat groups during the study. The primary function of eosinophils is combating the toxic substances in the body. Maximum decrease (-9.29\%) in lymphocytes levels was showed in R-SPI group (Figure 1). Means for effect of spirulina containing diets on eosinophils in rats group (Table 2) showed $1.35 \pm 0.28 \%$ eosinophils in rats fed on diet containing spirulina, $1.34 \pm 0.28 \%$ in rats group fed on spirulina protein isolates diet and $1.33 \pm 0.21 \%$ in control diet.

Wistar rats were fed on diets containing isoproteinic diets $(12 \% \mathrm{w} / \mathrm{w})$ having spirulina $(8.8,17.6$ and $26.4 \%)$ along with casein as control. The $26.4 \%$ spirulina incorporation showed

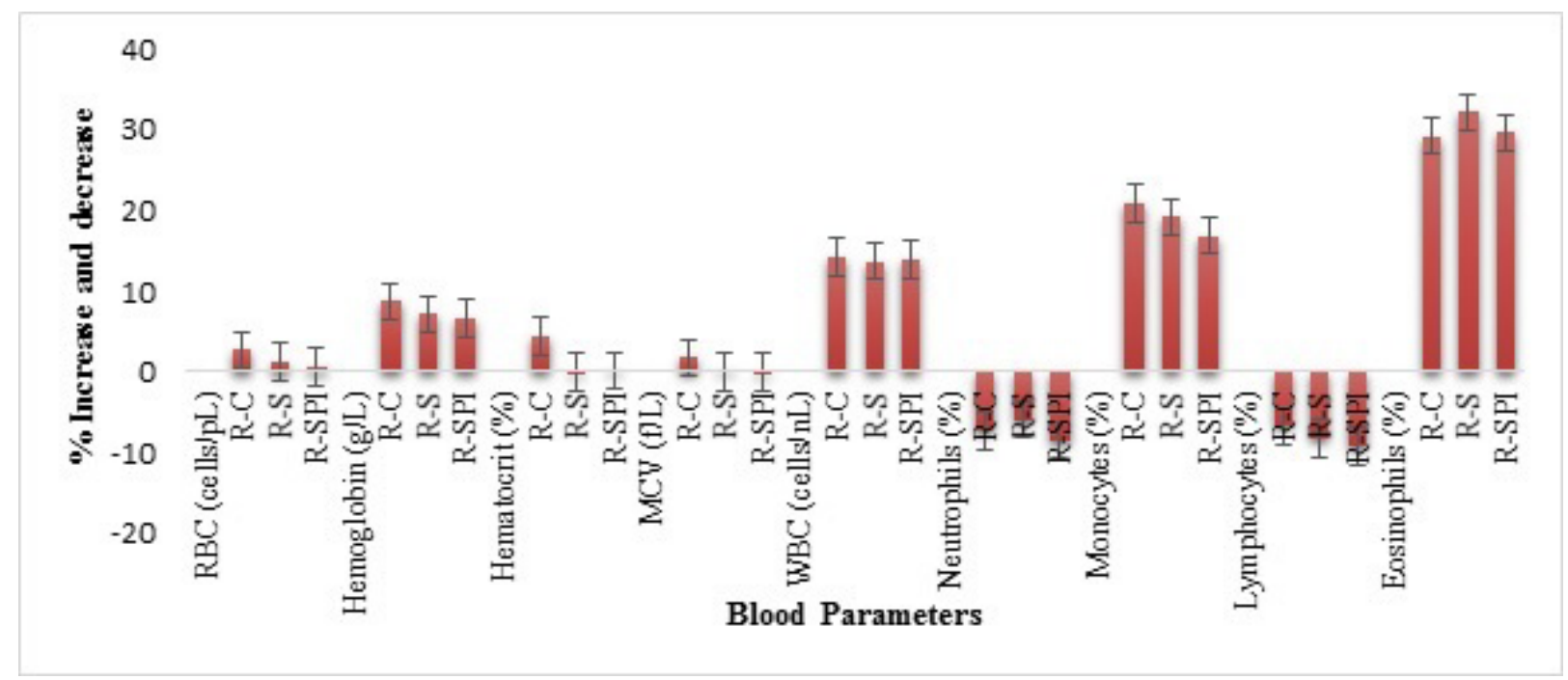

Figure 1. Percent Increase and decrease of blood parameters in rats fed with crude spirulina and purified protein of spirulina. R-C: Rats fed on control diet. R-S: Rats fed on diet containing spirulina. R-SPI: Rats fed on diet containing spirulina protein isolate. 
hematocrit (46.75\%) and hemoglobin (14.90\%) levels greater than the control diet. Non-significant differences were observed regarding monocytes among different groups. Mean values for lymphocytes ( 65.50 to $83 \%$ ), monocytes (1.35 to $3.85 \%$ ), eosinophils ( 0.5 to $3.85 \%)$, hematocrit ( 43.80 to $46.75 \%)$, hemoglobin (14.10 to $14.90 \%)$ and MCV (57.50 to 59\%) were noted in all rats groups. Moreover, it was observed that the spirulina percentage in the diet has direct association with the levels of erythrocytes; higher amounts of spirulina (26.4\%), elevated values were found for this blood index (Moreira et al., 2011).

In another study, Spirulina maxima was evaluated for possible toxicity by supplementing spirulina $(0,10,20$ or $30 \%)$ in rat diets for the period of 13 weeks. Hematology results did not revealed differences between the treated and control groups. However, diets containing $10 \%$ spirulina, showed slight increase in RBC (8.50 cells/pL), hemoglobin $(12.8 \mathrm{~g} / 100 \mathrm{~mL})$, neutrophils $(16.6 \%)$, eosinophils ( $0.4 \%)$, lymphocytes $(80.7 \%)$ and monocytes $(2.3 \%)$ in male rats at the end of study (Salazar et al., 1998). Spirulina was supplemented for the treatment of toxicity caused by lead $(\mathrm{Pb})$ and cadmium $(\mathrm{Cd})$ against leukemia and anemia. 50 rats randomly divided into 5 groups were fed on diets containing $\mathrm{Pb}$ and $\mathrm{Cd}$ alone as well as in combination with spirulina (300 mg/kg) along with control. Blood indices including RBC, WBC, hemoglobin and MCV were noted for all rat groups. There was improvement in the $\mathrm{WBC}$ and $\mathrm{MCV}$ as a result of spirulina supplementation reflecting the therapeutic worth of spirulina against leukemia and anemia (Simsek et al., 2009).

\subsection{Histopathology}

Histopathological examinations of body organs including livers, kidney and spleen of rats indicated normal pathological indicators in all groups confirming the positive role of spirulina supplementation revealed normal architecture of the liver, illustrated no abnormality in kidneys and spleen. The representative photomicrographs are shown (Figures 2, 3 and 4). The liver of rats exhibited no pathological change at the end of 45 days study. Overall, tissues exhibited normal hepaocytes with prominent nucleus and nuclei. Likewise, kidneys of rats exhibited mild degenerative changes in tubular epithelial cells. Furthermore, photomicrograph of spleen exhibiting disintegration of lymphocytes within the spleen along with hemocidrin deposition and central artery dilation.

Spirulina contains $\alpha$-lipoic acid, riboflavin, xanthophylls, phytopigments, superoxide dismutases enzyme, selenium, magnesium and manganese, which contribute to the antioxidant potential of spirulina (Bermejo et al., 2008; Banji et al., 2013). Free radical scavenging ability of Spirulina platensis is evident from the DPPH scavenging and $\beta$-carotene linoleic acid assay (Amarowicz et al., 2004; Ferruzzi, 2010). The results from several studies have supported utilization of spirulina as a diet supplement for the prevention of health problems due to the injuries produced by the free redicals (Bhat \& Madyastha, 2000; Mohan et al., 2006; El-Baz et al., 2013).

Likewise, nephrotoxicity (cisplatin-induced) protection in Wistar male rats was explored using orally administered spirulina $(1,000 \mathrm{mg} / \mathrm{kg})$ for 8 days and cisplatin $(6 \mathrm{mg} / \mathrm{kg}$ b.w.) once intraperitoneally on day 4 . Nephrotoxicity was appraised after 6 days of the cisplatin treatment by analyzing plasma urea, creatinine and histopathology. Kidneys from control rats illustrated no abnormality while cisplatin treated animals revealed proximal tubular necrosis, extensive epithelial vacuolization, swelling and tubular dilation and renal tubules with hyaline casts. The glomerulus and tubular epithelial changes were less sever in the group treated with cisplatin and spirulina as compared to cisplatin treated rats (Mohan et al., 2006).

Streptozotocin induced (60 mg/kg b.w.) diabetic rats were administered with crude extract of spirulina $(15 \mathrm{mg} / \mathrm{kg})$ for 45 days. Histopathological examination showed normal liver and kidneys in control as well as rats fed on spirulina. However, degenerative changes in hepatocytes were observed in liver of diabetic rats. Furthermore, group fed on spirulina ethanol

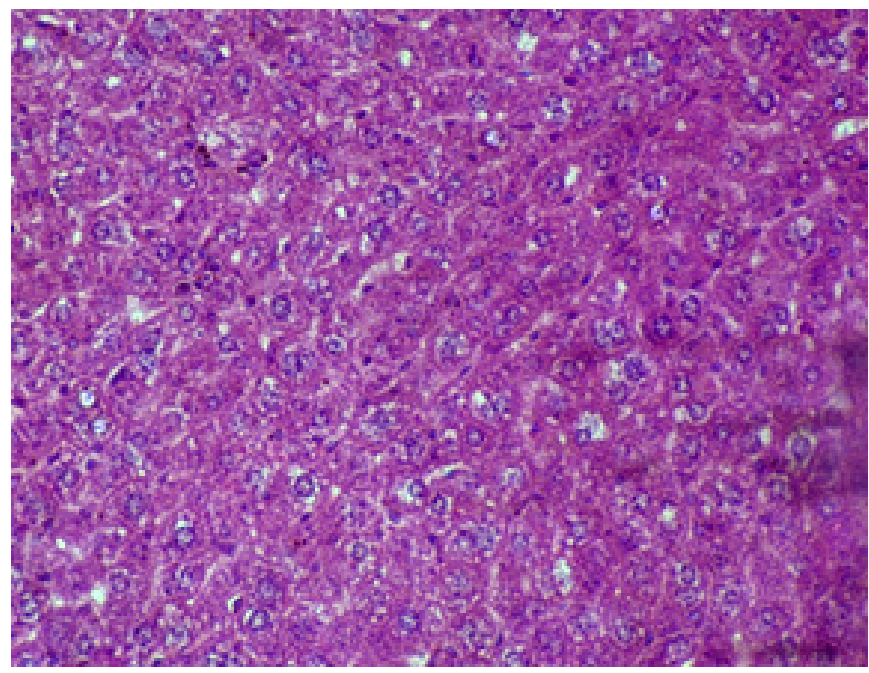

Figure 2. Photomicrograph of liver from rats fed on spirulina diet exhibiting normal hepaocytes with prominent nucleus and nuclei. X-200 H\&E (hematoxylin and eosin).

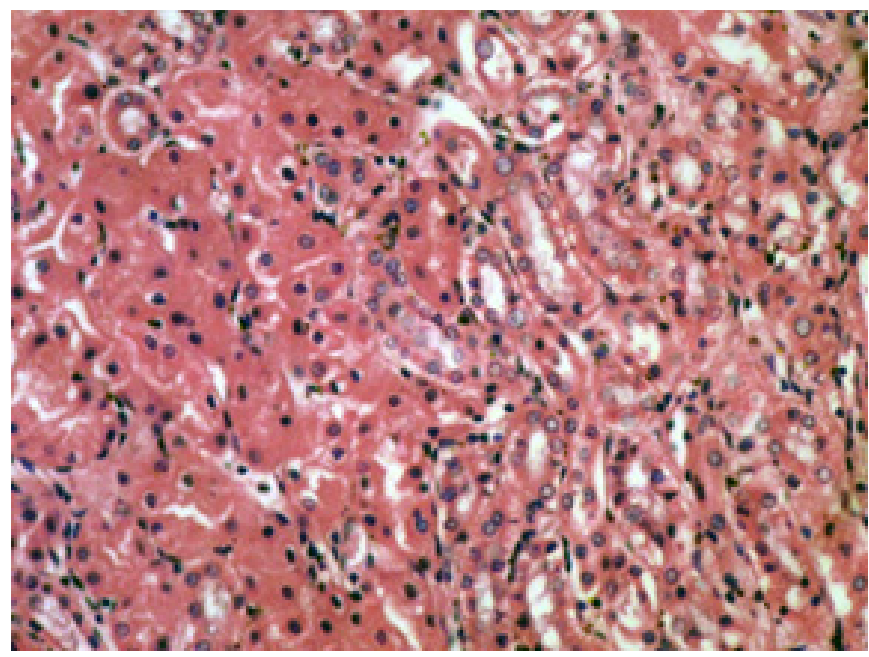

Figure 3. Photomicrograph of kidney from rats fed on spirulina diet exhibiting mild degenerative changes in tubular epithelial cells; cells have hyperchromatic nuclei. X-200 H\&E (hematoxylin and eosin). 


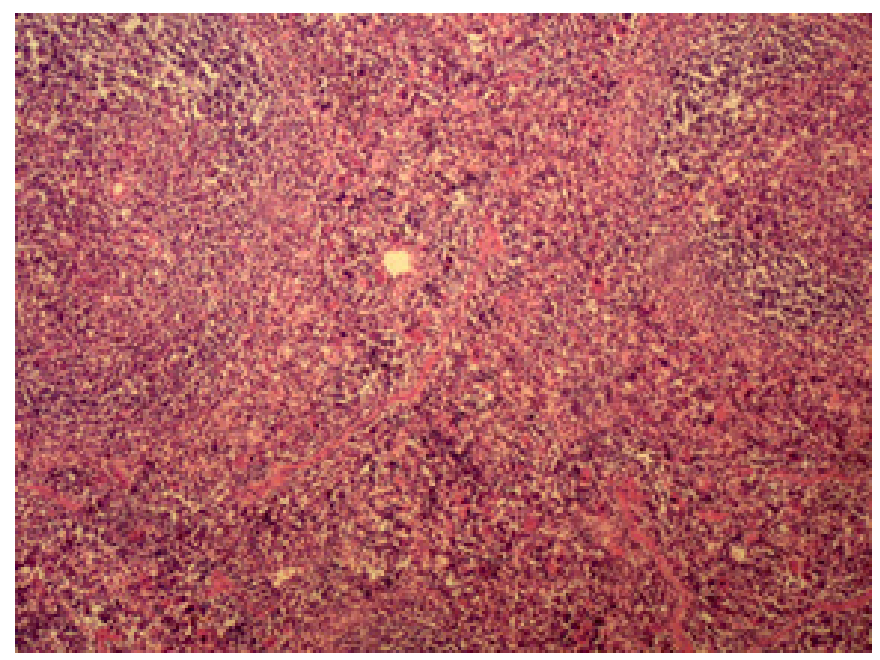

Figure 4. Photomicrograph of spleen from rats fed on spirulina diet exhibiting mild disintegration of lymphocytes within the spleen, hemocidrin deposition and central artery dilation. X-200 H\&E (hematoxylin and eosin).

extract and glibenclamide drug showed similar ordinary hepatic strands radiating from central vein and normal hepatocytes. On the other hand, kidneys of diabetic rats showed proliferation of mesangial cells and matrix of glumeroli, thickened arteriole and tubular dilatation, whilst treatment of diabetic rats with extract of spirulina showed normal mesangial cells and matrix of glumeroli, focal thickened arteriole and mild tubular dilatation (El-Baz et al., 2013).

In another study, blue green alga (BGA) was evaluated for in vitro and in vivo toxicity of Nostoc commune (NO) and Spirulina platensis (SP). For the purpose, male and female mice were fed on diets supplemented with $0,2.5$ and $5 \%$ of both algae for 6 months. Histopathological examinations of livers indicated that BGA did not cause major liver damage compared with control group. It is obvious from the results that $\mathrm{NO}$ and $\mathrm{SP}$ are free of microcystin and the long-term supplementation of BGA (5\%) can be carried without obvious toxic side effects. Furthermore, examination of liver revealed mild to moderate lipidosis after 6 months in control and experimental diets. Nevertheless, no other signs of liver damage were pragmatic in all groups (Yang et al., 2011).

Recently, spirulina was evaluated against lipopolysaccharide (LPS) potentiated alcoholic liver disease using 40 male albino Wister rats consuming spirulina ( $500 \mathrm{mg} / \mathrm{kg}$ b.w.) and ethanol $(5 \mathrm{~g} / \mathrm{kg}$ b.w.) alone and in combinations with LPS ( $3 \mathrm{mg} / \mathrm{kg}$ b.w.) to confirm the role of spirulina on hepatic marker enzymes in all groups. Co-administration of spirulina showed reduction in biochemical and histological changes and maintained hepatic architecture similar to that seen in the control. However, the liver sections of ethanol alone treated groups showed milk fatty inflammation and degeneration. Conversely, ethanol plus LPS intoxicated rats showed noticeable fat accumulation and fatty infiltration. On the other hand ethanol plus LPS rats cotreated with spirulina showed normal hepatocytes with mild portal inflammation, while control and spirulina alone treated rats showed normal architecture of the liver (Sarumathi et al., 2014).

\section{Conclusion}

The hematological profile and histopathological examination revealed that the rats feed on spirulina diet for 45 days had no sign of toxicity. So, it is obvious from the results that spirulina is safe for human consumption and we can use it in different food items like snacks, confectionary and bakery items to intensify their nutritional profile. Being a rich source of protein spirulina can be added in the diet of children that are suffering from malnutrition which is the challenge of the day.

\section{Acknowledgement}

This research was supported by Higher Educaction commission Pakistan and is the part of thesis submitted to University of Agriculture, Faisalabad, for the award of degree.

\section{References}

Amarowicz, R., Pegg, R. B., Rahimi-Moghaddam, P., Barl, B., \& Weil, J. A. (2004). Freeradical scavenging capacity and antioxidant activity of selected plant species from the Canadian prairies. Food Chemistry, 84(4), 551-562. http://dx.doi.org/10.1016/S0308-8146(03)00278-4.

Ambrozova, J. V., Misurcova, L., Vicha, R., Machu, L., Samek, D., Baron, M., Mlcek, J., Sochor, J., \& Jurikova, T. (2014). Influence of extractive solvents on lipid and fatty acids content of edible freshwater algal and seaweed products, the green microalga chlorella kessleri and the cyanobacterium spirulina platensis. Molecules (Basel, Switzerland), 19(2), 2344-2360. http://dx.doi.org/10.3390/molecules19022344. PMid:24566307.

Banji, D., Banji, O. J., Pratusha, N. G., \& Annamalai, A. R. (2013). Investigation on the role of Spirulina platensis in ameliorating behavioural changes, thyroid dysfunction and oxidative stress in offspring of pregnant rats exposed to fluoride. Food Chemistry, 140(1-2), 321-331. http://dx.doi.org/10.1016/j.foodchem.2013.02.076. PMid:23578649.

Beard, J. L. (2001). Iron biology in immune function, muscle metabolism and neuronal functioning. The Journal of Nutrition, 131(2S-2), 568-580. http://dx.doi.org/10.1093/jn/131.2.568S. PMid:11160590.

Bermejo, P., Pinero, E., \& Villar, A. M. (2008). Iron-chelating ability and antioxidant properties of phycocyanin isolated from a protean extract of spirulina platensis. Food Chemistry, 110(2), 436-445. http://dx.doi.org/10.1016/j.foodchem.2008.02.021. PMid:26049237.

Bhat, V. B., \& Madyastha, K. M. (2000). C-phycocyanin: a potent peroxyl radical scavenger in vivo and in vitro. Biochemical and Biophysical Research Communications, 275(1), 20-25. http://dx.doi.org/10.1006/ bbrc.2000.3270. PMid:10944434.

El-Baz, F. K., Aly, H. F., El-Sayed, A. L., \& Mohamed, A. A. (2013). Role of spirulina platensis in the control of glycemia in DM2 rats. International Journal of Scientific and Engineering Research, 4, 1731-1740.

Elmalawany, A. M., Salem, T. A., Mohamed, A. H., \& Osman, G. Y. (2014). Effect of blue green algae on some biochemical and hematological markers in mice. International Journal of Advanced Research, 2, 568-574.

Ferruzzi, M. G. (2010). The influence of beverage composition on delivery of phenolic compounds from coffee and tea. Physiology \& Behavior, 100(1), 33-41. http://dx.doi.org/10.1016/j.physbeh.2010.01.035. PMid:20138903.

Food and Drug Administration. (2003). Generally recognized as safe. Maryland: FDA. Retrieved from http://www.fda.gov/Food/ 
FoodIngredientsPackaging/GenerallyRecognizedasSafeGRAS/ GRASListings/ucm153674.htm

Francavilla, M., Trotta, P., \& Luque, R. (2010). Phytosterols from Dunaliella tertiolecta and Dunaliella salina: a potentially novel industrial application. Bioresource Technology, 101(11), 4144-4150. http://dx.doi.org/10.1016/j.biortech.2009.12.139. PMid:20110165.

Gerde, J. A., Wang, T., Yao, L., Jung, S., Johnson, L. A., \& Lamsal, B. (2013). Optimizing protein isolation from defatted and non-defatted Nannochloropsis microalgae biomass. Algal Research, 2(2), 145-153. http://dx.doi.org/10.1016/j.algal.2013.02.001.

Hutadilok-Towatana, N., Reanmongkol, W., \& Panichayupakaranant, P. (2010). Evaluation of the toxicity of Arthrospira (Spirulina platensis) extract. Journal of Applied Phycology, 22(5), 599-605. http://dx.doi. org/10.1007/s10811-009-9499-5.

Ibañez, E., \& Cifuentes, A. (2013). Benefits of using algae as natural sources of functional ingredients. Journal of the Science of Food and Agriculture, 93(4), 703-709. http://dx.doi.org/10.1002/jsfa.6023. PMid:23339029.

Jiwan, M. A., Duane, P., O’Sullivan, L., O'Brien, N. M., \& Aherne, S. A. (2010). Content and bioaccessibility of carotenoids from organic and non-organic baby foods. Journal of Food Composition and Analysis, 23(4), 346-352. http://dx.doi.org/10.1016/j.jfca.2009.12.014.

Kaur, K., Sachdeva, R., \& Kochhar, A. (2009). Effect of spirulina supplementation on the nutrient adequacy and health status of noninsulin-dependent diabetes mellitus male subjects. Ethno Medicine, 3(2), 119-126. http://dx.doi.org/10.1080/09735070.2009.11886348.

Ku, C. S., Yang, Y., Park, Y., \& Lee, J. (2013). Health benefits of bluegreen algae: prevention of cardiovascular disease and nonalcoholic fatty liver disease. Journal of Medicinal Food, 16(2), 103-111. http:// dx.doi.org/10.1089/jmf.2012.2468. PMid:23402636.

Li, Z. Y., Guo, S. Y., \& Li, L. (2006). Study on the process, thermodynamical isotherm and mechanism of $\mathrm{Cr}$ (III) uptake by Spirulina platensis. Journal of Food Engineering, 75(1), 129-136. http://dx.doi.org/10.1016/j. jfoodeng.2005.04.003.

Marles, R. J., Barrett, M. L., Barnes, J., Chavez, M. L., Gardiner, P., Ko, R., Mahady, G. B., Low Dog, T., Sarma, N. D., Giancaspro, G. I., Sharaf, M., \& Griffiths, J. (2011). United States pharmacopeia safety evaluation of spirulina. Critical Reviews in Food Science and Nutrition, 51(7), 593-604. http://dx.doi.org/10.1080/10408391003721719. PMid:21793723.

Mohan, I. K., Khan, M., Shobha, J. C., Naidu, M. U. R., Prayag, A., Kuppusamy, P., \& Kutala, V. K. (2006). Protection against cisplatininduced nephrotoxicity by spirulina in rats. Cancer Chemotherapy and Pharmacology, 58(6), 802-808. http://dx.doi.org/10.1007/ s00280-006-0231-8. PMid:16552571.

Moreira, L. M., Rocha, A. S. R., Ribeiro, C. L. G., Rodrigue, R. S., \& Soares, L. A. S. (2011). Nutritional evaluation of single-cell protein produced by spirulina platensis. African Journal of Food Science, $5,799-805$.

Ravi, M., Lata, D. S., Din, S. A., \& Solomon, F. D. P. (2010). The beneficial effects of spirulina focusing on its immunomodulatory and antioxidant properties. Nutrition and Dietary Supplements, 2, 73-83.

Salazar, M., Martınez, E., Madrigal, E., Ruiz, L. E., \& Chamorro, G. A. (1998). Subchronic toxicity study in mice fed spirulina maxima. Journal of Ethnopharmacology, 62(3), 235-241. http://dx.doi. org/10.1016/S0378-8741(98)00080-4. PMid:9849634.

Sarumathi, A., Sethupathy, S., \& Saravanan, N. (2014). The protective efficacy of spirulina against bacterial endotoxin potentiated alcoholic liver disease. Journal of Functional Foods, 9, 254-263. http://dx.doi. org/10.1016/j.jff.2014.04.026.

Simpore, F. A., Araujo, M. B., Moura, L. P., Garcia, A., Silva, C. M. S., Junior, R. C. V., Melo, F. C. L., \& Mello, M. A. R. (2011). Nutrition recovery with spirulina diet improves body growth and muscle protein of protein - restricted rats. International Journal of Nutrition and Metabolism, 3, 22-30.

Simpore, J., Kabore, F., Zongo, F., Dansou, D., Bere, A., Pignatelli, S., Biondi, D. M., Ruberto, G., \& Musumeci, S. (2006). Nutrition rehabilitation of undernourished children utilizing spiruline and misola. Nutrition Journal, 5(1), 1-7. http://dx.doi.org/10.1186/1475289*1-5-3. PMid:16430775.

Simsek, N., Karadeniz, A., Kalkan, Y., Keles, O. N., \& Unal, B. (2009). Spirulina platensis feeding inhibited the anemia and leucopenia induced lead and cadmium in rats. Journal of Hazardous Materials, 164(2-3), 1304-1309. http://dx.doi.org/10.1016/j.jhazmat.2008.09.041. PMid:18976856.

Steel, R. G. D., Torrie, J. H., \& Dickey, D. A. (1997). Principles and procedures of statistics. In R. G. D. Steel (Ed.), A biometrical approach (3rd ed., pp. 352-399). New York: McGraw Hill Book Co. Inc.

Sullivan, A. M. O., Callaghan, Y. C. O., Connor, T. P. O., \& Brien, N. M. O. (2011). The content and bioaccessibility of carotenoids from selected commercially available health supplements. The Proceedings of the Nutrition Society, 70(OCE3), 60-62. http://dx.doi.org/10.1017/ S0029665111001029.

Yamani, E., Kaba-Mebri, J., Mouala, C., Gresenguet, G., \& Rey, J. L. (2009). Use of spirulina supplement for nutritional management of HIV-infected patients: Study in Bangui, Central African Republic. Medecine Tropicale : Revue du Corps de Sante Colonial, 69(1), 6670. PMid:19499738.

Yang, Y., Park, Y., Cassada, D. A., Snow, D. D., Rogers, D. G., \& Lee, J. (2011). In vitro and in vivo safety assessment of edible blue-green algae, Nostoc commune Sphaeroides Kützing and Spirulina plantensis. Food and Chemical Toxicology, 49(7), 1560-1564. http://dx.doi. org/10.1016/j.fct.2011.03.052. PMid:21473896. 